\title{
Characterization of Proline-Containing $\alpha$-Helix (Helix F Model of Bacteriorhodopsin) by Molecular Dynamics Studies
}

\author{
R. Sankararamakrishnan and Saraswathi Vishveshwara \\ Molecular Biophysics Unit, Indian Institute of Science, Bangalore 560 012, India
}

\begin{abstract}
Many of the bilayer spanning segments of membrane transport proteins contain proline residues, and most of them are believed to occur in $\alpha$-helical form. A proline residue in the middle of an $\alpha$-helix is known to produce a bend in the helix, and recent studies have focused on characterizing such a bend at atomic level. In the present case, molecular dynamics (MD) studies are carried out on helix $F$ model of bacteriorhodopsin (BR) Ace-(Ala $)_{7^{-}}$ Trp-(Ala $)_{2}$-Tyr-Pro-(Ala $)_{2}$-Trp-(Ala $)_{8}-\mathrm{NHMe}$ and compared with Ace-(Ala) $)_{7}-$ Trp-(Ala $)_{2}-T_{y r}-(A l a)_{3}-$ Trp-(Ala $)_{8}-\mathrm{NHMe}$ in which the proline is replaced by alanine. The bend in the helix is characterized by structural parameters such as kink angle $(\alpha)$, wobble angle $(\theta)$, virtual torsion angle ( $\rho)$, and the hydrogen bond distance $d$ $\left(0_{p-3} \ldots N_{p+1}\right)$. The average values and the flexibility involved in these parameters are evaluated. The correlation among the bend related parameters are estimated. The equilibrium side chain orientations of tryptophan and tyrosine residues are discussed and compared with those found in the recently proposed model of bacteriorhodopsin. Finally, a detailed characterization of the bend in terms of secondary structures such as $\alpha_{I}, \alpha_{I I}$ and goniometric helices are discussed, which can be useful in the interpretation of the experimental results on the secondary structures of membrane proteins involving the proline residue.

(C) 1993 Wiley-Liss, Inc.
\end{abstract}

Key words: proline-containing $\alpha$-helix, backbone-bend parameters, correlation between parameters, side chain conformation, helix $F$ of bacteriorhodopsin

\section{INTRODUCTION}

The proline residue in proteins has always been associated with important structural features. ${ }^{1}$ Its presence in the middle of a right-handed $\alpha$-helix, however, has only recently been recognized and characterized, made possible from the studies of the crystal structure analysis, ${ }^{2,3}$ energy minimization, ${ }^{4}$ molecular dynamics, ${ }^{5}$ and free energy ${ }^{6}$ simulations. (c) 1993 WILEY-LISS, INC.
Apart from its presence in globular proteins, the proline residue in the middle of the membrane spanning segments of a number of transport proteins has been identified. ${ }^{7}$ The secondary structure of such membrane spanning segments has been characterized as $\alpha$-helical in bacteriorhodopsin $(B R)^{8}$ and other membrane proteins are also known to have proline-containing $\alpha$-helices. ${ }^{9-12}$ The possible structural and/or functional role of prolines in transmembrane helices has been recently discussed. ${ }^{13}$

Three of the membrane spanning helices (B, C, F) in $\mathrm{BR}$ contain proline residues in the middle. These helices contain the side chains that have been recognized to be functionally important. ${ }^{14-16}$ During the photocycle, large-scale motion of these helices has been proposed to take place. ${ }^{17-21}$ The characterization of the dynamical properties of the individual helices can help in understanding some of the aspects of the photocycle at the molecular level. In this work, helix F model of bacteriorhodopsin is investigated and the features are compared with the helix in which the proline residue is replaced by an alanine residue. The geometrical features of prolinecontaining $\alpha$-helices are distinctly different from those of a standard $\alpha$-helix. ${ }^{3}$ Since the occurrence of such helices are common in membrane transport proteins, ${ }^{7}$ it was felt that an analysis of the geometrical parameters would be useful in modeling and understanding the three-dimensional architecture of membrane proteins. Such an analysis has aided in recognizing specific parameters involved in the formation of kink and in quantitatively evaluating the flexibility introduced in the $\alpha$-helix by a proline residue. Also, the secondary structural characteristics of proteins having proline-containing helices are discussed in the light of the results obtained from the molecular dynamics studies.

\section{METHODS}

Molecular dynamics (MD) simulations for the helix $F$ model of bacteriorhodopsin (BR) were per-

Received December 13, 1991; revision accepted March 6, 1992.

Address reprint requests to Dr. Saraswathi Vishveshwara, Molecular Biophysics Unit, Indian Institute of Science, Bangalore 560012 , India. 


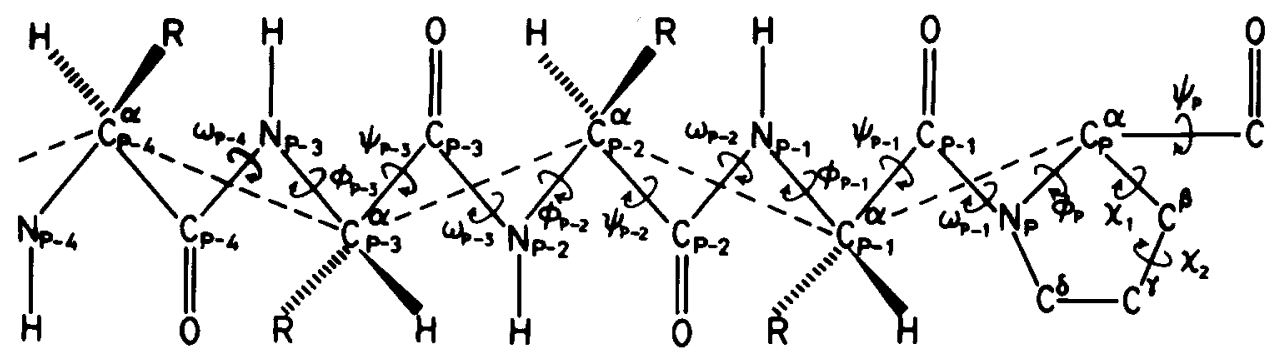

Fig. 1. The conformational parameters of a polypeptide chain containing a proline residue in the middle. $R$ represents the side chain of the residue. The notations $\phi, \psi$, and $\omega$ refer to the standard backbone torsion angles and $x_{3}$ and $\chi_{2}$ define the proline ring

conformation. The $\mathrm{C}^{\alpha}$ atoms defining the virtual torsional angle are joined by broken lines. The symbol $\rho$ in the text represents the virtual torsional angle $C_{p-3}^{\alpha}-C_{p-2}^{\alpha}-C_{p-1}^{\alpha}-C_{p}^{\alpha}$.
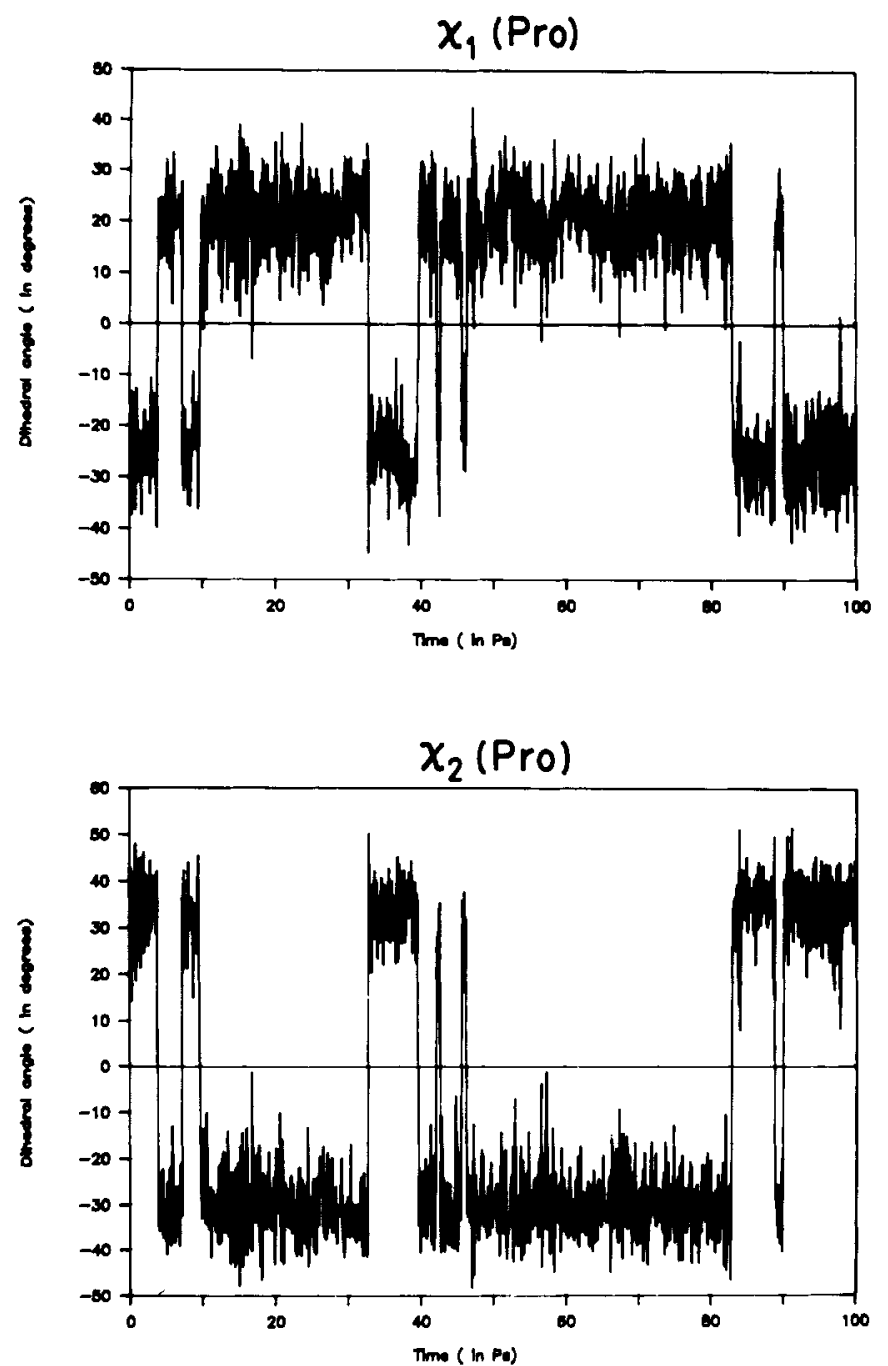

Fig. 2. MD trajectories of proline pucker parameters ( $\chi_{1}$ and $\chi_{2}$ of proline residue).

formed using the AMBER program, ${ }^{22,23}$ which was run on a VAX 8810 machine. The system chosen for the molecular dynamics studies is Ace-(Ala) $)_{7}$-Trp-

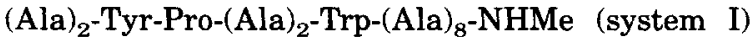
in which the proline, tyrosine, and tryptophan resi- dues were retained in the same relative positions with respect to the helix $\mathrm{F}$ of $\mathrm{BR}$, and the other residues were replaced by alanine residues. This model provides an $\alpha$-helix model long enough to span the membrane bilayer. For comparison, MD simulations 
TABLE I. Average and rms Fluctuations of Backbone Internal Parameters (in Degrees) in the Proline Region

\begin{tabular}{lccc}
\hline $\begin{array}{l}\text { Internal } \\
\text { parameters }\end{array}$ & System I & System II & $\begin{array}{c}\text { Crystal structure } \\
\text { average* }\end{array}$ \\
\hline$\phi_{\mathrm{p}-4}$ & $-61.3( \pm 9.2)$ & $-58.2( \pm 8.5)$ & -60.9 \\
$\psi_{\mathrm{p}-4}$ & $-38.7( \pm 12.2)$ & $-47.9( \pm 8.3)$ & -30.9 \\
$\phi_{\mathrm{p}-3}$ & $-67.4( \pm 12.1)$ & $-58.2( \pm 9.1)$ & -75.7 \\
$\psi_{\mathrm{p}-3}$ & $-44.2( \pm 10.0)$ & $-48.9( \pm 8.5)$ & -33.9 \\
$\phi_{\mathrm{p}-2}$ & $-69.2( \pm 11.4)$ & $-57.7( \pm 9.0)$ & -73.0 \\
$\psi_{\mathrm{p}-2}$ & $-44.4( \pm 12.1)$ & $-50.0( \pm 8.5)$ & -36.4 \\
$\phi_{\mathrm{p}-1}$ & $-44.9( \pm 11.5)$ & $-55.6( \pm 8.6)$ & -51.8 \\
$\psi_{\mathrm{p}-1}$ & $-58.5( \pm 8.2)$ & $-52.5( \pm 8.6)$ & -51.1 \\
$\phi_{\mathrm{p}}$ & $-62.3( \pm 10.2)$ & $-56.8( \pm 9.1)$ & -60.8 \\
$\psi_{\mathrm{p}}$ & $-44.7( \pm 10.0)$ & $-48.6( \pm 8.5)$ & -34.0 \\
$\omega_{\mathrm{p}-2}$ & $-171.3( \pm 8.0)$ & $176.7( \pm 6.6)$ & -175.4 \\
$\mathrm{~N}_{\mathrm{p}-1}-\mathrm{C}_{\mathrm{p}-1}^{\alpha}-\mathrm{C}_{\mathrm{p}-1}$ & $114.3( \pm 3.1)$ & $110.5( \pm 3.0)$ & 115.3 \\
$\mathrm{C}_{\mathrm{p}-1}^{\alpha}-\mathrm{C}_{\mathrm{p}-1}-\mathrm{N}_{\mathrm{p}}$ & $121.2( \pm 2.6)$ & $117.5( \pm 2.8)$ & 118.6 \\
\hline
\end{tabular}

*The average was obtained as a result of crystal structure analysis of proline-containing $\alpha$-helical segments from 14 different high-resolution protein structures. Details in ref. 3.

TABLE II. Average and rms Fluctuations of Conformational Parameters (in Degrees) Depending Upon the Proline Puckering

\begin{tabular}{lccrr}
\hline & & & \multicolumn{2}{c}{ Minimized structures } \\
\cline { 3 - 5 } Parameters & Pro-Down & Pro- $U p$ & -39.7 & -46.7 \\
\hline$\phi_{\mathrm{p}-1}$ & $-43.3( \pm 11.3)$ & $-48.2( \pm 11.2)$ & -60.3 & -54.1 \\
$\psi_{\mathrm{p}-1}$ & $-60.5( \pm 7.4)$ & $-54.1( \pm 8.3)$ & -177.3 & 175.2 \\
$\omega_{\mathrm{p}-1}$ & $-178.1( \pm 6.4)$ & $176.5( \pm 7.6)$ & -59.7 & -49.9 \\
$\phi_{\mathrm{p}}$ & $-59.4( \pm 8.6)$ & $-51.5( \pm 10.2)$ & -41.6 & -47.6 \\
$\psi_{\mathrm{p}}$ & $-43.1( \pm 9.7)$ & $-48.1( \pm 9.7)$ & 23.4 & -28.6 \\
$\chi_{1}$ (Pro) & $21.2( \pm 7.3)$ & $-25.5( \pm 7.6)$ & -33.6 & 35.7 \\
$\chi_{2}$ (Pro) & $-30.6( \pm 7.3)$ & $33.2( \pm 8.3)$ & &
\end{tabular}

TABLE III. Average and rms Fluctuations of Intrahelical Hydrogen Bond Lengths (in Angstroms) and Hydrogen Bond Angles (in Degrees)

\begin{tabular}{lcc}
\hline & System I & System II \\
\cline { 2 - 3 } Description of & $\mathrm{O} \ldots \mathrm{H}$ Distance & $\mathrm{O} \ldots \mathrm{H}$ Distance \\
hydrogen bond & $\mathrm{O} \ldots \mathrm{H}-\mathrm{N}$ Angle & $\mathrm{O} \ldots \mathrm{N}-\mathrm{H}$ Angle \\
\hline $\mathrm{O}_{\mathrm{p}-8} \ldots \mathrm{HN}_{\mathrm{p}-4}-\mathrm{N}_{\mathrm{p}-4}$ & $1.92( \pm 0.13)$ & $1.91( \pm 0.13)$ \\
& $163.4( \pm 9.3)$ & $162.4( \pm 9.3)$ \\
$\mathrm{O}_{\mathrm{p}-7} \ldots \mathrm{HN}_{\mathrm{p}-3}-\mathrm{N}_{\mathrm{p}-3}$ & $1.99( \pm 0.23)$ & $1.90( \pm 0.13)$ \\
& $154.4( \pm 14.8)$ & $161.1( \pm 9.5)$ \\
$\mathrm{O}_{\mathrm{p}-6} \ldots \mathrm{HN}_{\mathrm{p}-2}-\mathrm{N}_{\mathrm{p}-2}$ & $1.94( \pm 0.17)$ & $1.93( \pm 0.16)$ \\
& $156.4( \pm 12.5)$ & $161.8( \pm 9.5)$ \\
$\mathrm{O}_{\mathrm{p}-5} \ldots \mathrm{HN}_{\mathrm{p}-1}-\mathrm{N}_{\mathrm{p}-1}$ & $1.94( \pm 0.17)$ & $1.92( \pm 0.13)$ \\
$\mathrm{O}_{\mathrm{p}-4} \ldots \mathrm{HN}_{\mathrm{p}}-\mathrm{N}_{\mathrm{p}}$ & $156.9( \pm 13.3)$ & $162.1( \pm 9.3)$ \\
& $\mathrm{Absent}$ & $1.88( \pm 0.12)$ \\
$\mathrm{O}_{\mathrm{p}-3} \ldots \mathrm{HN}_{\mathrm{p}+1}-\mathrm{N}_{\mathrm{p}+1}$ & & $162.1( \pm 9.3)$ \\
& $3.48( \pm 0.63)$ & $1.92( \pm 0.14)$ \\
$\mathrm{O}_{\mathrm{p}-2} \ldots \mathrm{HN}_{\mathrm{p}+2}-\mathrm{N}_{\mathrm{p}+2}$ & $159.7( \pm 10.3)$ & $161.9( \pm 9.7)$ \\
$\mathrm{O}_{\mathrm{p}-1} \ldots \mathrm{HN}_{\mathrm{p}+3}-\mathrm{N}_{\mathrm{p}+3}$ & $1.95( \pm 0.18)$ & $1.95( \pm 0.16)$ \\
\hline
\end{tabular}



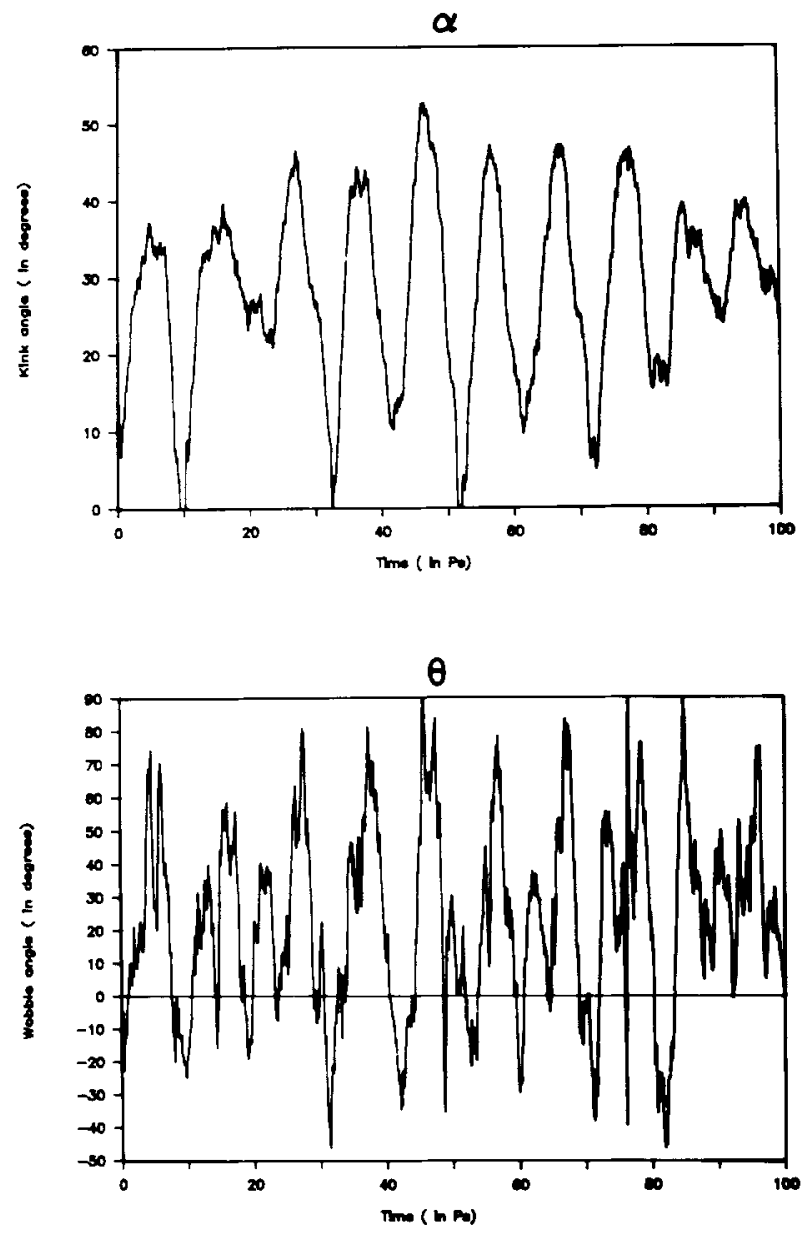

Fig. 3. MD trajectories of bend related parameters (kink angle $(\alpha)$, wobble angle $(\theta)$, virtual torsion angle $(\rho)$, hydrogen bond distance $d\left(O_{p-3} \ldots N_{p+1}\right)$ and $\left(\phi_{p-1}\right)$. Figure continues on page 30 .

were also performed on Ace-(Ala) $)_{7}$-Trp-(Ala) $)_{2}$-Tyr$(\mathrm{Ala})_{3}$-Trp-(Ala) $)_{8}$-NHMe (system II) to investigate the role of the proline residue in the middle of an $\alpha$-helix in general and the importance of side chains in the proline-containing helix $\mathrm{F}$ of $\mathrm{BR}$ in particular.

The internal parameters for the starting structure of system I were taken from ref. 4. The energy was minimized using the AMBER minimization module until the rms gradient of the energy was less than $0.1 \mathrm{Kcal} / \mathrm{mol} \AA$. The structure thus obtained was taken as the starting point for the simulation. For system II, the minimized ideal $\alpha$-helical structure was considered as the starting point.

Initially, random velocities were assigned to each atom using the Maxwellian distribution corresponding to a low temperature. The systems were equilibrated to $300 \mathrm{~K}$ over a period of $25 \mathrm{ps}$ and continued for a further $100 \mathrm{ps}$. The AMBER MD program uses a Verlet leapfrog algorithm. ${ }^{24}$ A time step of 0.001 ps was chosen in this study. All hydrogen atoms were explicitly included and hence the force field corresponding to an all atom model ${ }^{25}$ was used. All bonds involving hydrogen atoms were constrained using the algorithm SHAKE, and both the simulations were performed in vacuum. Although the model peptide we have chosen is a transmembrane segment of a membrane protein bacteriorhodopsin, only about one-third of the helical face is in contact with the lipid bilayer. Since the remaining part is exposed to the inner core of the protein, which contains polar and ionizable amino acid residues, a distance-dependent dielectric constant $\epsilon=\mathbf{R}_{\mathrm{ij}}$ was used in our calculations. The output from the MD run contained a total of 1,000 "snapshots" of the atomic coordinates during $100 \mathrm{ps}$ evolution time with each snapshot taken at $0.1 \mathrm{ps}$ interval for both the systems I and II.

The notation of the conformational parameters is shown in Figure 1. The dihedral angles $\chi_{1}$ and $\chi_{2}$ of proline residue is related to the $u p$ or down pucker of proline with $\left(\chi_{1}, \chi_{2}\right)$ assuming $(-v e,+v e)$ and $(+v e$, $-v e)$ in the $u p$ and down conformations, respectively. Apart from the standard parameters, virtual torsional angles of $\mathrm{C}^{\alpha}$ atoms are also depicted. The 

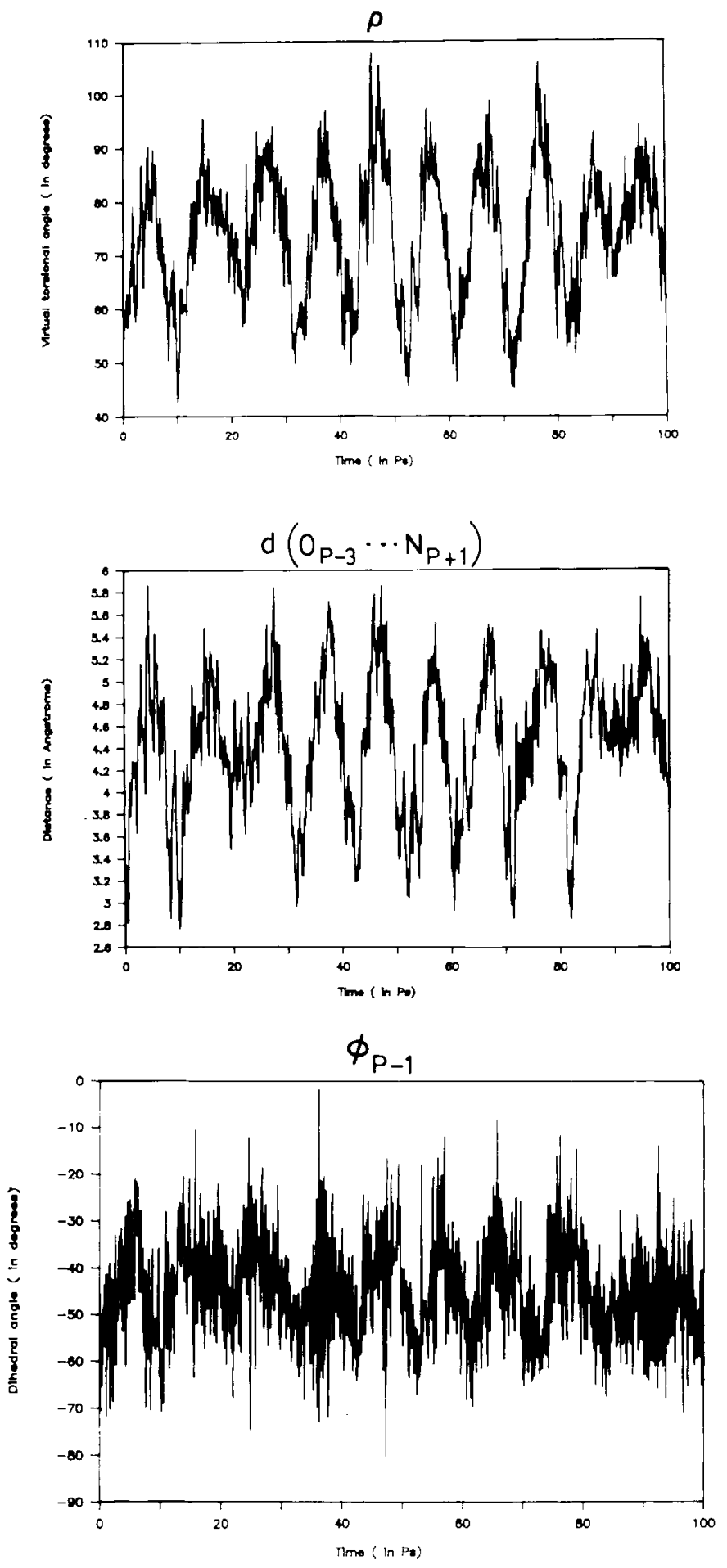

Fig. 3. Legend appears on page 29

averages and rms fluctuations of internal parameters and hydrogen bond parameters were obtained from the AMBER MD analysis program, whereas virtual torsion angles of $\mathrm{C}^{\alpha}$ atoms were calculated in a separate program for both system I and system II.
The backbone internal parameters in the proline region, the side chain dihedral angles, the hydrogen bond parameters, and the virtual torsional angles of $\mathrm{C}^{\alpha}$ atoms were analyzed. Our recent crystal structure analysis ${ }^{3}$ and MD studies on proline-containing 


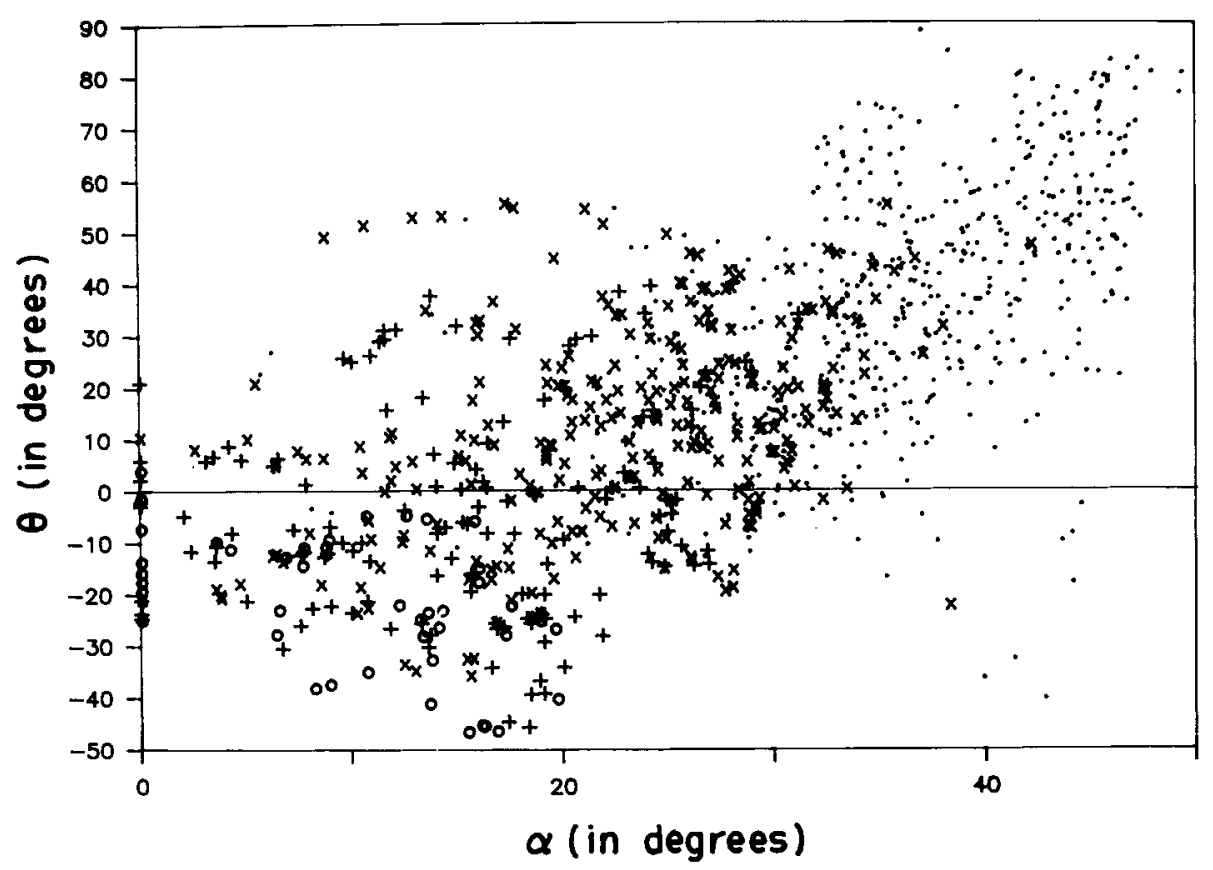

Fig. 4. A plot of kink angle $(\alpha)$ vs. wobble angle $(\theta)$ obtained from MD simulated structures. The points are plotted in different symbols depending on the hydrogen bond distance $d\left(O_{p-3} \ldots N_{p+1}\right)$. The symbols ' 0 ', ' + ', ' $x$ ' and ' $:$ ' correspond to $d\left(\mathrm{O}_{p-3} \ldots \mathrm{N}_{\mathrm{p}+1}\right)<3.2 \AA, 3.2$ to $3.8 \AA, 3.8$ to $4.4 \AA$ and $>4.4 \AA$, respectively.

helical segments ${ }^{5}$ have shown that the virtual torsion angle $\mathrm{C}_{\mathrm{p}-3}^{\alpha}-\mathrm{C}_{\mathrm{p}-2}^{\alpha}-\mathrm{C}_{\mathrm{p}-1}^{\alpha}-\mathrm{C}_{\mathrm{p}}^{\alpha}$ (designated as $\rho$ ) deviates from the average value of a standard $\alpha$-helix. Hence this parameter has been studied in detail. The dependence of backbone dihedral angles on proline puckering was also investigated in system I by considering all the 1,000 MD simulated structures.

Eight structures from the 100 ps simulation of system I were submitted to energy minimization procedures. Five structures lie in the range 45 to 55 ps in which proline is in the down conformation and the other three, in the range 85 to $95 \mathrm{ps}$, where proline is in $u p$ conformation. Using the AMBER minimization module, the steepest descent method was used for the first 50 cycles and followed by the conjugate gradient method until convergence was obtained. The resulting structures were further minimized by the Newton-Raphson method using the AMBER NMODE module. All the conformational parameters for these minimized structures were analyzed.

The bend introduced by proline in the righthanded $\alpha$-helix has been characterized mainly by two parameters viz. kink angle and wobble angle (designated as $\alpha$ and $\theta$, respectively). ${ }^{3,26}$ The kink angle is the angle between two helical axes: one from the $\mathrm{N}$-terminal to proline (helix $\mathrm{I}$ ) and the other from proline to C-terminal (helix II). An algorithm suggested by Chou et al. ${ }^{27}$ was used to find the helix axis. The wobble angle is the angle that defines the orientation of helix II in three-dimen- sional space with respect to helix I. The detailed method for evaluating the wobble angle is described in ref. 3 . The main steps involved in the calculation of wobble angle $(\theta)$ are as follows: (1) helix I was made parallel to $\mathrm{Z}$-axis with $\mathrm{C}_{\mathrm{p}}^{\alpha}$ atom as the origin; (2) helix I was rotated about $\mathrm{z}$-axis to make the radius vector, joining the $C_{p}^{\alpha}$ atom and the helix axis of helix I, collinear with positive $\mathrm{X}$-axis; (3) a point was projected on the XY-plane from helix axis of helix II; and (4) the angle made by the line, joining the origin and the projected point, with the $\mathrm{X}$-axis is the wobble angle $(\theta)$.

The parameters virtual torsion angle $(\rho), \mathrm{d}\left(\mathrm{O}_{\mathrm{p}-3}\right.$ $\ldots \mathrm{N}_{\mathrm{p}+1}$ ) and $\phi_{\mathrm{p}-1}$, which are related to kink angle and wobble angle were studied in detail. The correlation coefficient $\mathrm{C}$ between any two parameters $\mathrm{A}$ and $B$ is given by the formula

$$
C=\frac{\sum_{i=1}^{N}\left(A_{i}-\bar{A}\right)\left(B_{i}-\bar{B}\right)}{\sum_{i=1}^{N}\left|\left(A_{i}-\bar{A}\right)\left(B_{i}-\bar{B}\right)\right|}
$$

where $\bar{A}$ and $\bar{B}$ are averages and $A_{i}$ and $B_{i}$ are the values of the $i^{\text {th }}$ simulated point for the parameters $A$ and $B$, respectively, in a total of $\mathrm{N}$ points. The correlation coefficient matrix was obtained for all the bend related parameters. Using this matrix and the trajectories, the interrelationship of these parameters has been discussed.

Separate programs were written to evaluate kink 

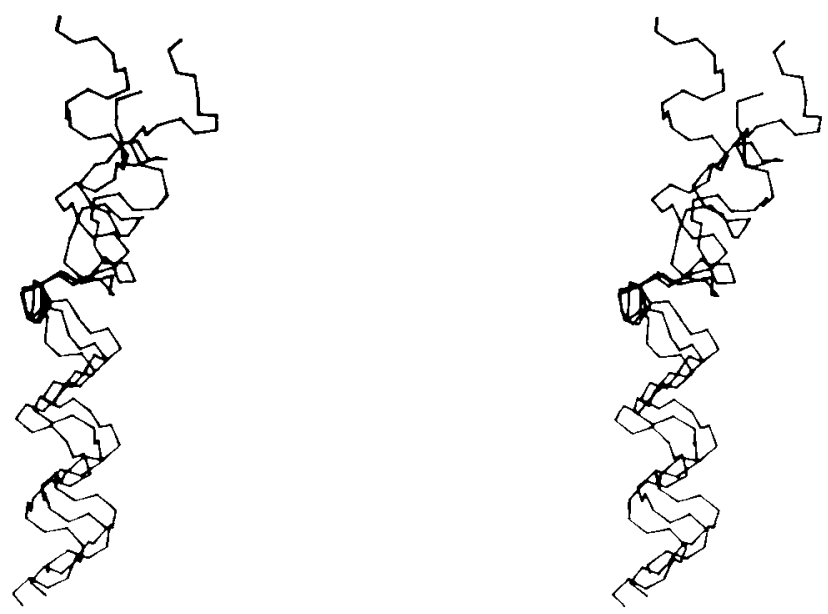

Fig. 5. A stereo diagram of three MD simulated structures for system I (only backbone atoms and proline side chain are plotted) with the values of $[\alpha, \theta]$ being $\left[5.5^{\circ},-2.0^{\circ}\right],\left[30.5^{\circ}, 22.0^{\circ}\right]$ and $\left[52.2^{\circ}, 63.01\right.$

angle, wobble angle, to get the trajectories of different parameters and to calculate correlation coefficient between any two parameters.

\section{RESULTS AND DISCUSSION Backbone Internal Parameters}

The proline residue in the middle of a right-handed $\alpha$-helix is known to introduce perturbations in some of the bond angles and dihedral angles of the backbone. From the previous studies ${ }^{3-5}$ the $(\phi, \psi)$ values corresponding to $\phi_{\mathrm{p}}{ }_{4}$ to $\psi_{\mathrm{p}}$ region have shown distortions from the standard values (idealized theoretical value ${ }^{28} \phi=-57.5^{\circ}, \psi=-47.5^{\circ}$, crystal structure average of all helical residues in globular proteins $^{29} \phi=-63.8^{\circ}( \pm 6.6), \psi=-41.0^{\circ}( \pm 7.2)$. The MD average and the rms deviation of parameters $\phi_{\mathrm{p}}{ }_{4}$ to $\psi_{\mathrm{p}}, \mathrm{N}_{\mathrm{p}}{ }_{1}-\mathrm{C}_{\mathrm{p}-1}^{\alpha}-\mathrm{C}_{\mathrm{p}, 1}$ and $\mathrm{C}_{\mathrm{p}-1}^{\alpha}-\mathrm{C}_{\mathrm{p}}{ }_{1}-\mathrm{N}_{\mathrm{p}}$ for the molecule Ace-(Ala) $)_{7}$-Trp-(Ala) $)_{2}$-Tyr-Pro(Ala) ${ }_{2}$-Trp-(Ala) $)_{8}$-NHMe (system I) are given in Table I. A comparison has been made with the molecular dynamics average for Ace-(Ala) $)_{7}$-Trp(Ala) $)_{2}$-Tyr-(Ala) ${ }_{3}$-Trp-(Ala) ${ }_{8}$-NHMe (system II) and the recent crystal structure average on proline-containing $\alpha$-helices. ${ }^{3}$ The values confirm the trend reported previously that, $\phi_{\mathrm{p}} 1$ is less negative and $\psi_{\mathrm{p}}$, is more negative than the standard values. In general $\phi_{\mathrm{p}-3}, \phi_{\mathrm{p}-2}$ are more negative and $\psi_{\mathrm{p}}$, $\psi_{p}, 3$, and $\psi_{\mathrm{p}}$ are less negative than the standard values. The peptide dihedral angle $\omega_{\mathrm{p}-2}$ has taken an average value of $-171.3^{\circ}$ with rms fluctuation of $8.0^{\circ}$. The rms fluctuations in parameters $\phi_{\mathrm{p}-4}$ to $\psi_{\mathrm{p}}$ are larger in the proline-containing helix (system I) compared to the non-proline-containing helix (system II). The bond angles $\mathrm{N}_{\mathrm{p}-1} \cdot \mathrm{C}_{\mathrm{p}-1}^{\alpha}-\mathrm{C}_{\mathrm{p} 1}$ and $\mathrm{C}_{\mathrm{p}-1}^{\alpha}-\mathrm{C}_{\mathrm{p}}, \mathrm{1}^{-}-\mathrm{N}_{\mathrm{p}}$ are generally wider than the standard values $^{30}\left(\mathrm{~N}-\mathrm{C}^{\mathrm{\alpha}}-\mathrm{C}=108.0\right.$ to $111.0^{\circ} ; \mathrm{C}^{\mathrm{\alpha}}-\mathrm{C}-\mathrm{N}=$ $115.0^{\circ}$ ) with the crystal structure average of proline- containing helices given in Table I slightly differing from the MD average.

\section{Proline Puckering Parameters}

The proline ring fluctuates between the $u p$ and down conformation during the simulation period. This is represented by the trajectories of the dihedral angles $\chi_{1}$ and $\chi_{2}$ of the proline residue (Fig. 2). Some of the parameters $\left(\phi_{p}, \psi_{p}, \omega_{p} 1, \phi_{p}\right.$ and $\left.\psi_{p}\right)$ in the proline region indicate preferential values depending on the proline pucker and the MD averages of these values are given in Table II. A few structures from the MD simulation were selected for energy minimization as described in Methods. The structures minimize either to the up or to the doun conformation with almost same energy --327.5 $\mathrm{Kcal} / \mathrm{mole}$ ). However the parameters that are found to be different in MD average values have clearly different values even after minimization (Table II). The $\omega_{p}$ i deviates from planarity to a slightly greater extent in the up conformation than in the down conformation.

\section{Bend Characterizing Parameters}

Although well-defined changes are noticed in the above mentioned internal parameters, it is difficult to get an idea of the bend in the helix due to proline by examining a single internal parameter. The general characteristics can be measured in terms of other parameters such as virtual torsional angle

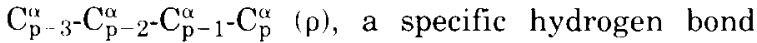
$\mathrm{N}_{\mathrm{p}, 1} \ldots \mathrm{O}_{\mathrm{p}-3}$, which is weakened due to proline, kink angle $(\alpha)$, and wobble angle $(\theta)$. The analysis of and the correlation among these parameters are discussed in this section.

The MD average of the virtual torsion angle $p$ is $74^{\circ}$ with maximum rms fluctuation of $12^{\circ}$ in system 

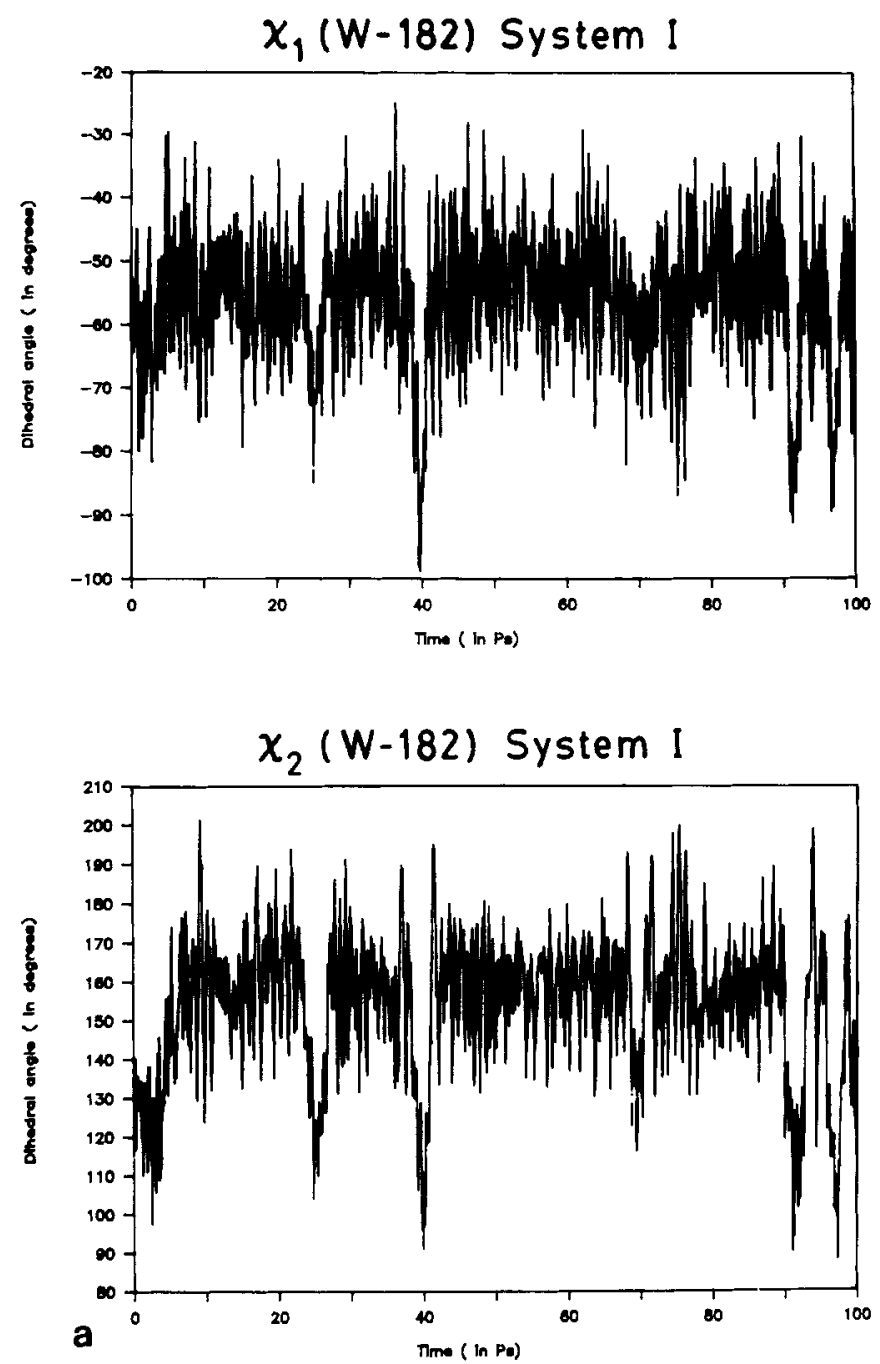

Fig. 6. (a) MD trajectories of $\chi_{1}$ and $\chi_{2}$ of W-182 for system I. (b) MD trajectories of $\chi_{1}$ and $\chi_{2}$ of W-182 for system II. Figure continues on page 34 .

I. The averages of other virtual torsional angles of system I and all the virtual torsion angles of system II are close to the ideal $\alpha$-helical value ${ }^{31}$ of $50^{\circ}$ and have less rms fluctuations. Higher value and maximum deviation in $\rho$ indicates that the kink starts from the helical turn that ends with proline residue and that region is more flexible. Further, the proline-containing helices are known to lack two hydrogen bonds, ${ }^{26}$ one due to the absence of the amide proton on proline nitrogen and another between $\mathrm{N}_{\mathrm{p}+1}$ and $\mathrm{O}_{\mathrm{p}-3}$. The hydrogen bond lengths $\left(\mathrm{O}_{\mathrm{p}-8}\right.$ $\ldots \mathrm{HN}_{\mathrm{p}-4}$ to $\mathrm{O}_{\mathrm{p}-1} \ldots \mathrm{HN}_{\mathrm{p}+3}$ ) and the corresponding $\mathrm{N}-\mathrm{H}$. . . O bond angles are given in Table III for system I and system II. The lack of the $\mathrm{O}_{\mathrm{p}-4} \ldots \mathrm{N}_{\mathrm{p}}$ hydrogen bond for system $I$ is obvious and the average $\mathrm{O}_{\mathrm{p}-3} \ldots \mathrm{HN}_{\mathrm{p}+1}$ distance is $3.48( \pm 0.63) \AA$. Apart from the longer $\mathrm{O}_{\mathrm{p}-3} \ldots \mathrm{HN}_{\mathrm{p}+1}$ distance, some of the hydrogen bond angles in the proline region assume smaller values $\left(\approx 155.0^{\circ}\right)$ than the standard one $\left(164.2^{\circ}\right.$ for an ideal $\alpha$-helix ${ }^{32} ; 161^{\circ}-$ $162^{\circ}$ for system II). Also, the rms deviations of these parameters are greater indicating fluctuations in this region. This is in agreement with the recent ${ }^{1} \mathrm{H}$ NMR studies ${ }^{33}$ on melittin in which the proline has been identified as the residue imparting flexibility to the helix.

The kink angle $(\alpha)$ is a direct measure of the bend in the helix and the wobble angle $(\phi)$ gives an idea about the mutual orientation of the helical segments below proline and above proline. The trajectories of these parameters along with those of $\phi_{\mathrm{p}-1}, \rho$ and $\mathrm{d}\left(\mathrm{O}_{\mathrm{p}-3} \ldots \mathrm{HN}_{\mathrm{p}+1}\right)$ are given in Figure 3 for system I. The MD average kink angle is $28.5^{\circ}( \pm 11.7)$ and wobble angle is $22.9^{\circ}$ ( \pm 28.8 ). All these parameters vary frequently in the range of a straight helix to that of bent one. Such fluctuations were also observed by ${ }^{1} \mathrm{H}$ NMR studies on melittin. ${ }^{34}$ The occurrence of proline in the signal and energy transduc- 

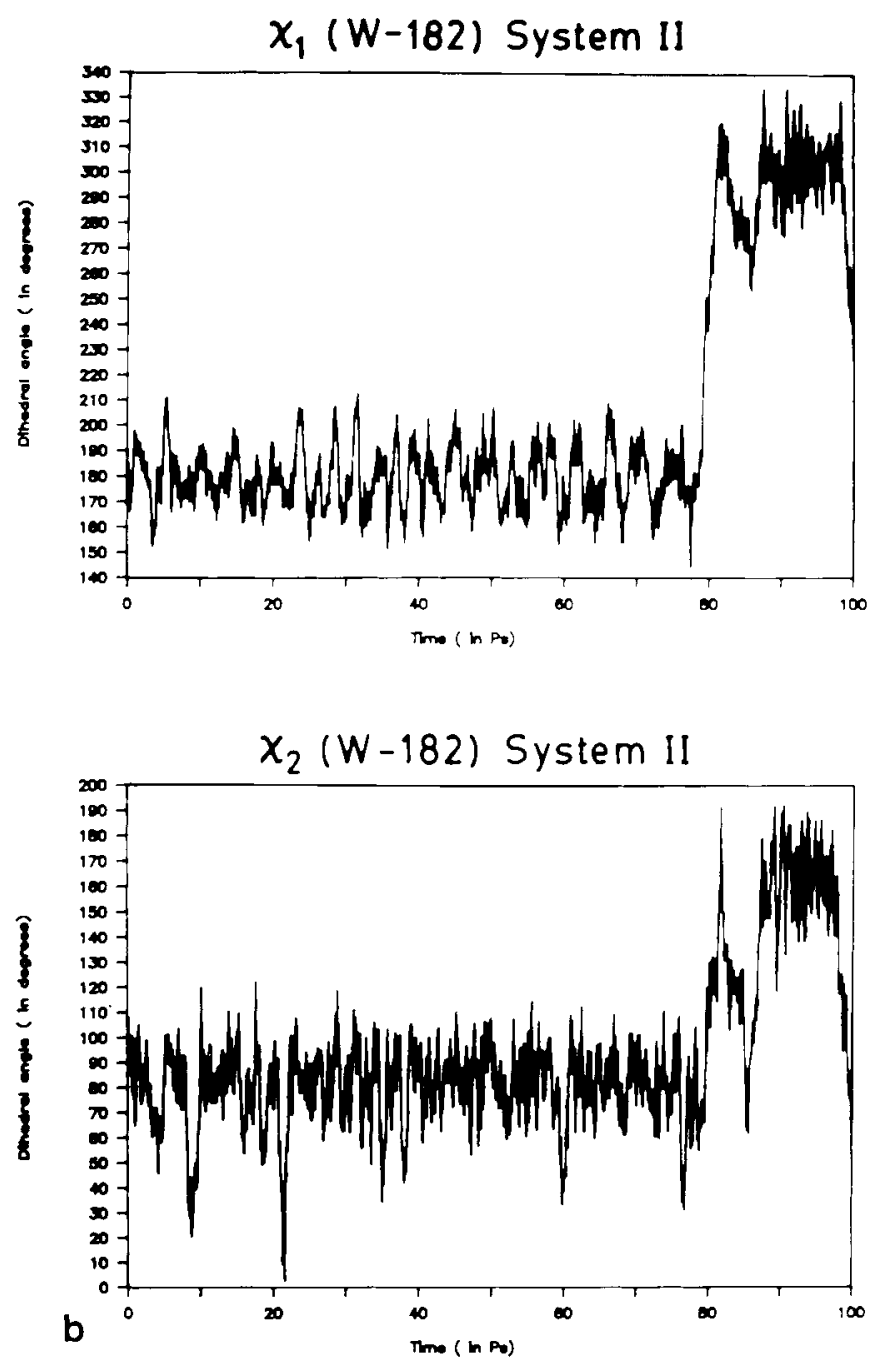

Fig. 6b. Legend appears on page 33

ing proteins ${ }^{7}$ and channel forming peptides like alamethicin ${ }^{35}$ is significant from its structural and furctional point of view. The presence of proline in $\alpha$-helices allows for changes in pore sizes. The present observations suggest that conformational changes can occur by adjusting the kink and the wobble angles and hence can play an important functional role.

Structures with varying kink angle ( $\alpha=0$ to $\left.50^{\circ}\right)$ and wobble angles $\left(\theta=-20\right.$ to $\left.+70^{\circ}\right)$ obtained during MD simulations were minimized as described in Methods. All the structures minimized with $\alpha=$ $30.9^{\circ}$ and $\theta=27.6^{\circ}$. This indicates a broad shallow minimum around the minimized structure. This is in agreement with the results of the free energy simulation studies in which the free energy difference was found to be small ${ }^{6}$ for a varying kink angle $15-$ $45^{\circ}$ in a 14-residue $\alpha$-helix containing proline in the nineth position. (However, the kink in this study was introduced by varying the hydrogen bond distance $d\left(\mathrm{~N}_{\mathrm{p}-1} \ldots \mathrm{O}_{\mathrm{p}-5}\right)$ instead of $\left.\mathbf{d}\left(\mathrm{N}_{\mathrm{p}+1} \ldots \mathrm{O}_{\mathrm{p}}{ }_{3}\right).\right)$
There is a significant correlation between many of the parameters that have been discussed here. The correlation coefficients between $\alpha, \theta, \phi_{p}, p$, $\mathrm{d}\left(\mathrm{O}_{\mathrm{p}-3} \ldots \mathrm{HN}_{\mathrm{p}+1}\right)$ are given in Table IV. All these parameters are highly correlated. The coorelation of $\phi_{\mathbf{p}-1}$ with the other parameters is, however, less in comparison. This indicates that the bend introduced in the helix due to proline is a cumulative effect of variations in the number of backbone internal parameters in the proline region. The values of $\alpha, \theta$, and $\mathrm{d}\left(\mathrm{O}_{\mathrm{p}-3} \ldots . \mathrm{HN}_{\mathrm{p}+1}\right)$ for the MD simulated structures in which the correlation among these parameters is more explicit have been plotted (Fig. 4). The negative $\theta\left(-50^{\circ}-0^{\circ}\right)$ and smaller $\mathrm{d}\left(\mathrm{O}_{\mathrm{p}} ; 3 \ldots\right.$ $\left.\mathrm{HN}_{\mathrm{p}+1}\right)\left(<3.2 \mathrm{~A}^{\circ}\right)$ values are found for smaller $\alpha$ values $\left(<20^{\circ}\right)$. The $\theta$ values assume more positive values and the $\mathrm{d}\left(\mathrm{O}_{\mathrm{p}-3} \ldots \mathrm{HN}_{\mathrm{p}+1}\right)$ becomes longer $\left(>4.4 \mathrm{~A}^{\circ}\right)$ for larger $\alpha$ values. The plot exhibits the range and the extreme values that can be taken up by a proline-containing helix during the MD simulation. The MD average, the crystal structure 
TABLE IV. Correlation Coefficients Between Various Bend Related Parameters

\begin{tabular}{lccccc}
\hline & $\alpha$ & $\theta$ & $\phi_{\mathbf{b}-1}$ & $\rho$ & $\mathrm{d}\left(\mathrm{O}_{\mathrm{n}-3} \ldots \mathrm{N}_{\mathrm{b}+1}\right)$ \\
\hline$\alpha$ & 1.000 & 0.861 & 0.589 & 0.967 & 0.973 \\
$\theta$ & & 1.000 & 0.333 & 0.751 & 0.892 \\
$\phi_{\mathrm{p}-1}$ & & & 1.000 & 0.639 & 0.559 \\
$\rho$ & & & & 1.000 & 0.960 \\
$\mathrm{~d}\left(\mathrm{O}_{\mathrm{p}-3} \ldots \mathrm{N}_{\mathrm{p}+1}\right)$ & & & & & 1.000 \\
\hline
\end{tabular}

average of proline-containing helices, ${ }^{3}$ and the minimized values of $\alpha$ and $\theta$ fall in the range of $20-30^{\circ}$ and $-30-+30^{\circ}$, respectively. A stereo diagram of system I with varying $\alpha$ and $\theta$ is given in Figure 5.

\section{Analysis of Side Chain Conformations}

The above studies on the characterization of internal parameters and the bend are applicable to any proline-containing $\alpha$-helix including those that span membranes. Helix F of BR has Tyr-185, Trp182, and Trp-189 in the Pro-186 neighborhood, and these residues have been identified as functionally important to the retinal binding pocket. ${ }^{16}$ The spatial arrangement of these aromatic residues play an important role in interacting with retinal. In the present study, the inherent dynamical behavior of these residues are characterized.

The MD simulation for system I was started with all side chains (Trp-182, -189, and Tyr-195) in their extended conformation. A similar starting point was also considered for system II. The trajectories of the two dihedral angles $\chi_{1}$ and $\chi_{2}$ for Trp-182, -189, and $\chi_{1}$ for Tyr-185 are shown in Figures 6-8 for both systems I and II.

In Figure 6a, although the extended conformation with $\chi_{1}=180.0^{\circ}$ for Trp-182 was the starting point, soon it assumed that value $\chi_{1} \simeq-60^{\circ}$. A comparison of $\mathrm{MD}$ average structure with those from $\mathrm{BR}$ model (Henderson, personal communication) is given in Table V. The preference for $x_{1}$ of Trp-182 to be in the $-60^{\circ}$ region seems to be inherent for helix $\mathrm{F}$ since even in the absence of an environmental effect as found from $\mathrm{MD}$ simulation, this value is assumed, which is close to trans orientation in nonproline helix (system II). The $\chi_{1}$ of Tyr-185, in contrast, has remained as trans in $\mathrm{MD}$ simulation of both systems I and II and is in the $-60^{\circ}$ region in the BR structure. The MD average of $\chi_{1}$ of Trp-189 is in the trans orientation in system I, system II, and in the BR model proposed by Henderson et al. ${ }^{8}$ However, the trajectories of $\chi_{1}$ of Trp-182 (Fig. 6b) and Trp-189 (Fig. 8b) for system II show that other conformations are also accessed for a short time during the simulation. Such type of transtitions were not observed in system $I$, perhaps due to restrictions brought out by the proline residue.

A stereo diagram of system I with different values of $\chi_{1}$ for Trp-182 is given in Figure 9a. A similar diagram for system II in which the Trp-182 and -189 are plotted in different conformations as obtained by MD simulation (Fig. 9b). It is evident that the equilibrium orientation of these side chains is different in system I and system II. Thus the bend introduced by proline influences the equilibrium side chain conformations. A superposition of $\mathrm{MD}$ equilibrated system I with the structure of helix F in Henderson's BR model $^{8}$ (with only Trp-182, Tyr-185, and Trp-189 side chains) is shown in Figure 9c. Tyr-185 conformation is different in the two structures because it interacts with Asp-212 of helix G in BR, whereas the helix F model (system I) is considered in isolation in the present MD studies. It should, however, be noted that the comparison of the present results with the BR model proposed by Henderson et al ${ }^{8}$ has limitations because of the low accuracy of the structure and also the simulations were carried out on the molecule (system I) in vacuum in which only aromatic side chains of helix $F$ were considered.

\section{Analysis of the Nature of Proline-Containing Helix}

Although proline-containing helices in globular proteins and membrane proteins have been identified as $\alpha$-helical in nature, there are several ways in which they differ from an ideal $\alpha$-helix. From the present MD studies and from crystal structure analysis, ${ }^{2,3}$ it has become possible to characterize the structural properties of proline-containing helices. In order to carry out a detailed characterization, the properties of $\alpha$-helices in general are outlined below.

Conformational energy calculations show ${ }^{36}$ that a trough of low energy extends from $\phi=-47^{\circ}, \psi=$ $-60^{\circ}$ to $\phi=-88^{\circ}, \psi=-25^{\circ}$ for an $\alpha$-helix. Though the dihedral angles in the proline region fall within this trough, they indeed belong to "different types of $\alpha$-helical structures."

The standard $\alpha$-helix proposed by Arnott and Wonacott $^{28}$ is usually referred as $\alpha_{\mathrm{I}}$-helix. The other type of helix in the right-handed $\alpha$-helical region corresponds to the second of two possible solution for the dihedral angles of a helix with constant $n$ (number of residues per turn) and $h$ (the height per residue). This helix is referred to as $\alpha_{1 I}$-helix and was first proposed by Nemethy et al. ${ }^{37}$ The helical parameters of standard $\alpha_{1}$ and $\alpha_{I I}$ helices are given in Table VI. A comparison of these parameters show 

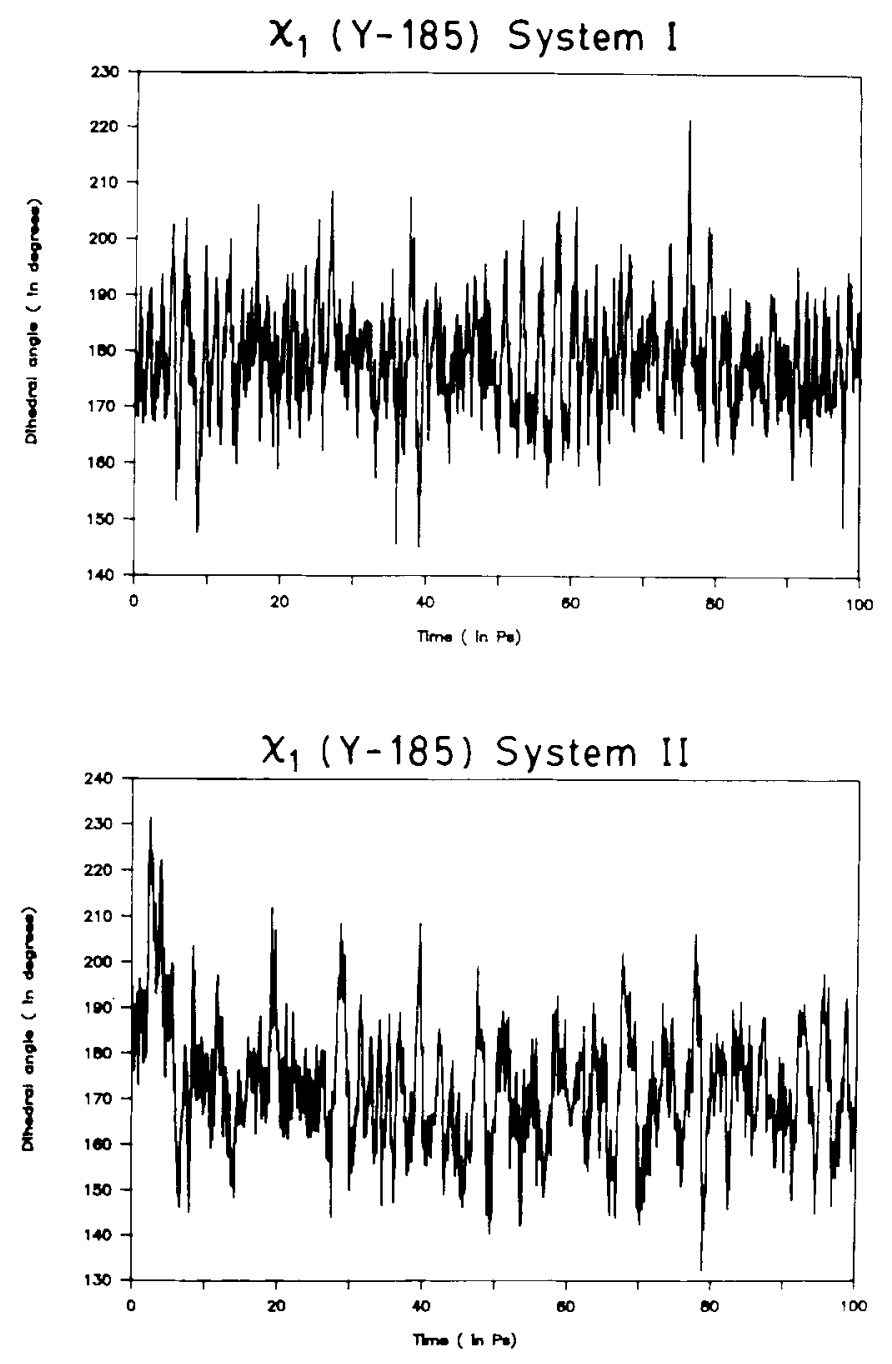

Fig. 7. MD trajectories of $\chi_{1}$ of $Y-185$ for system I and II.

differences in the $\phi, \psi$ angles and hydrogen bond parameters. In $\alpha_{I I}$-helix the hydrogen bonds are slightly weaker since the plane of the peptide unit is tilted with respect to helix axis and the $\mathrm{NH}$ group of this helix points towards the axis. The peptide unit is nearly parallel in the $\alpha_{I}$-helix. The third type of helix in the $\alpha$-helical region is designated as a goniometric helix ${ }^{38}$ in which the values of $\phi$ and $\psi$ of $\alpha_{1}$-helix interchange almost exactly (i.e., $\phi=$ $-47.5^{\circ}, \psi=57.5^{\circ}$ ) with small changes resulting in the helical parameters.

The nature of the proline-containing helix can be characterized in terms of the above different $\alpha$-helical structures. The analysis of backbone internal parameters are discussed in the first section of Results and Discussion. In fact, the average values of the dihedral angles $\left(\phi_{\mathrm{p}}, 3, \psi_{\mathrm{p} .3}\right)$ and $\left(\phi_{\left.\mathrm{p}, 2, \psi_{\mathrm{p}-2}\right)}\right)$ are close to those for the $\alpha_{I I}$ helix (Table I). As a result, the hydrogen bond parameters for residues $\mathrm{p}-2$ and p-3 are also close to those for the $\alpha_{11}$-helix (Table
III). The average of the hydrogen bond angle $\mathrm{NHO}$ is between that of $\alpha_{1}$ and $\alpha_{11}$ helices and the rms fluctuations of all the parameters (described in Table III) show that these residues can access both $\alpha_{1}$ and $\alpha_{I I}$ structures. The values of $\left(\phi_{p}, l_{1}, l_{p}\right)$ are close to the goniometric helix. The other parts of the helix show that the $(\phi, \psi)$ values are close to those for the $\alpha_{1}$-helix. This can be compared with those parameters obtained from the MD studies of system II, in which all the $(\phi, \psi)$ angles remain close to $\alpha_{1}$-helix throughout the simulation.

The deviation in the value of the virtual torsion angle $\rho$ from the standard value can be explained if the proline-containing helix is considered as a mixture of different $\alpha$-helical structures. The virtual torsion angles of $\mathrm{C}^{\mathrm{x}}$ atoms for various standard $\alpha$ helical structures and their mixtures are given in Table VII. It is clear that both $\alpha_{1}$ and $\alpha_{I I}$ have the same value $50^{\circ}$ though the $\phi, \downarrow$ angles are different. Similarly this value for the goniometric helix is al- 

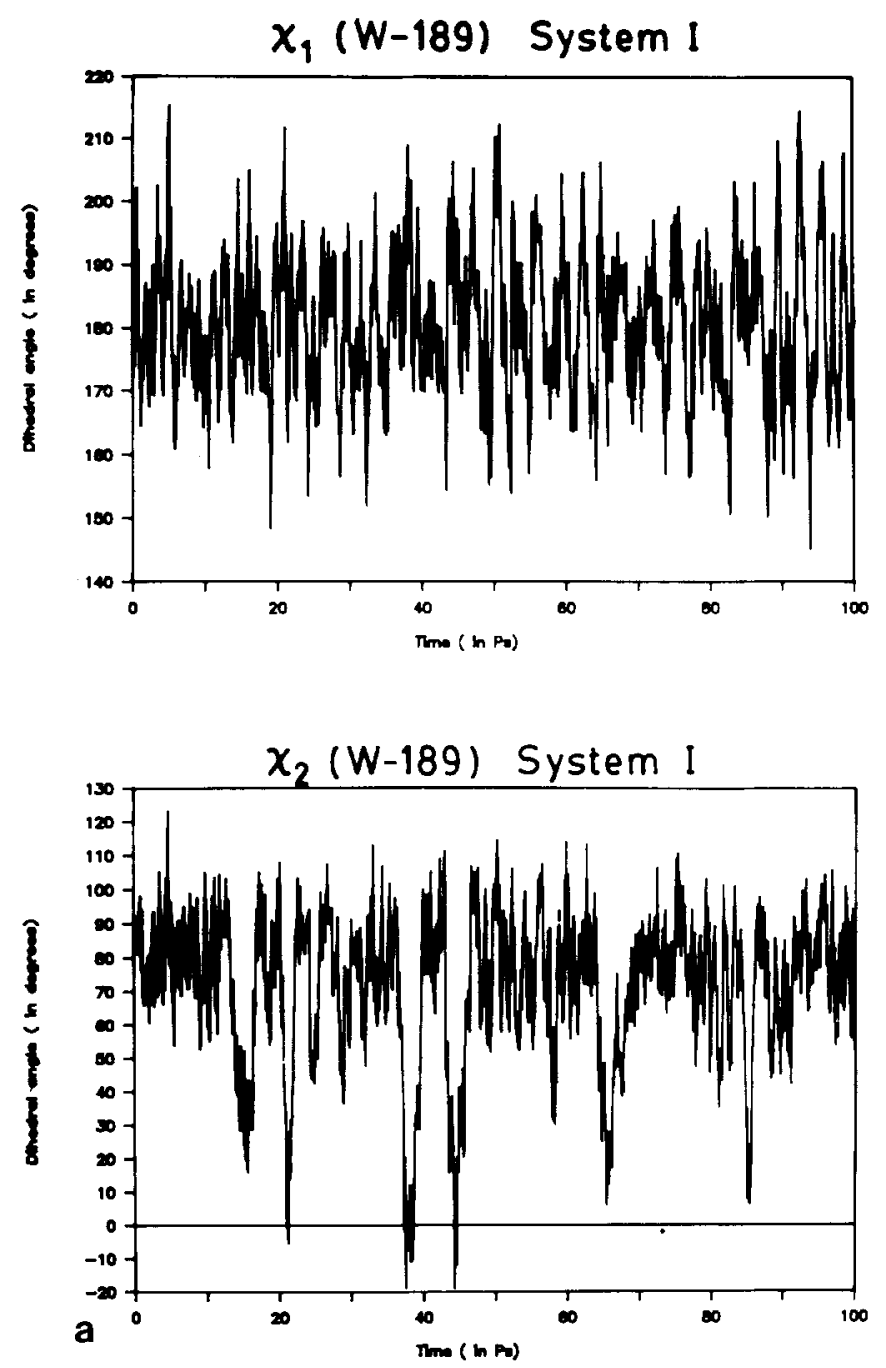

Fig. 8. (a) MD trajectories of $\chi_{1}$ and $\chi_{2}$ of W-189 for system I. (b) MD trajectories of $\chi_{1}$ and $\chi_{2}$ of W-189 for system II. Figure continues on page 38 .

most the same as that for the $\alpha_{\mathrm{I}}$ and $\alpha_{\mathrm{II}}$ helices. However, the virtual torsion angle $\mathrm{C}_{i}^{\alpha}-\mathrm{C}_{\mathrm{i}+1^{-}}^{\alpha}-\mathrm{C}_{\mathrm{i}+2^{-}}^{\alpha}$ $\mathrm{C}_{i+3}^{\alpha}$ has the value $68^{\circ}$ when residues $i, i+1$, are in the $\alpha_{\mathrm{Ir}}$-helical, $\mathrm{i}+3$ in the $\alpha_{\mathrm{I}}$-helical conformation and residue $i+2$ is in the goniometric conformation. This is analogous to $\rho$ in the proline-containing helix. Thus the proline-containing helix is mainly $\alpha_{I}$ in character with pronounced $\alpha_{11}$ and goniometric helical character in the helical turn ending with the proline residue. The MD studies have shown that fluctuations in this region are higher, with the values approaching near $\alpha_{\mathrm{I}}$ character at times.

High-resolution crystal structures and analysis of proteins containing proline in the middle of $\alpha$-helix are slowly emerging. A number of experimental studies characterizing the secondary structures of membrane proteins with proline-containing helices have been carried out. ${ }^{39}$ However, the secondary structural information derived from these studies has not been precise. The shift and the intensity differences in amide I and amide II IR bands in BR, almethicin, and other membrane proteins ${ }^{39}$ suggest a deviation from the ideal $\alpha_{\mathrm{I}}$-helical structure. However, no unique structure has been arrived at using this technique. In the case of $\mathrm{BR}$, a mixture of $\alpha_{I}+\alpha_{I I},{ }^{40} \alpha_{I}+\beta,{ }^{41} \alpha_{I}+3_{10},{ }^{42}$ and predominantly $\alpha_{\text {II }}{ }^{43}$ structures have been suggested. Far-UV CD spectra of BR also suggest that the secondary structure of $\mathrm{BR}$ is not pure $\alpha_{\mathrm{I}}$-helix, but has substantial $\alpha_{\text {II }}$ character. ${ }^{40}$ Nevertheless, the exact position and nature of the deviation become available only from high-resolution crystal structures. The crystal structure analysis of globular proteins ${ }^{3}$ and the energy minimization studies ${ }^{4}$ have given more details on the precise structural details of proline-containing $\alpha$-helices. Further, the present MD simulation has given information on the flexibility in different parts of these helices. These studies also give the 

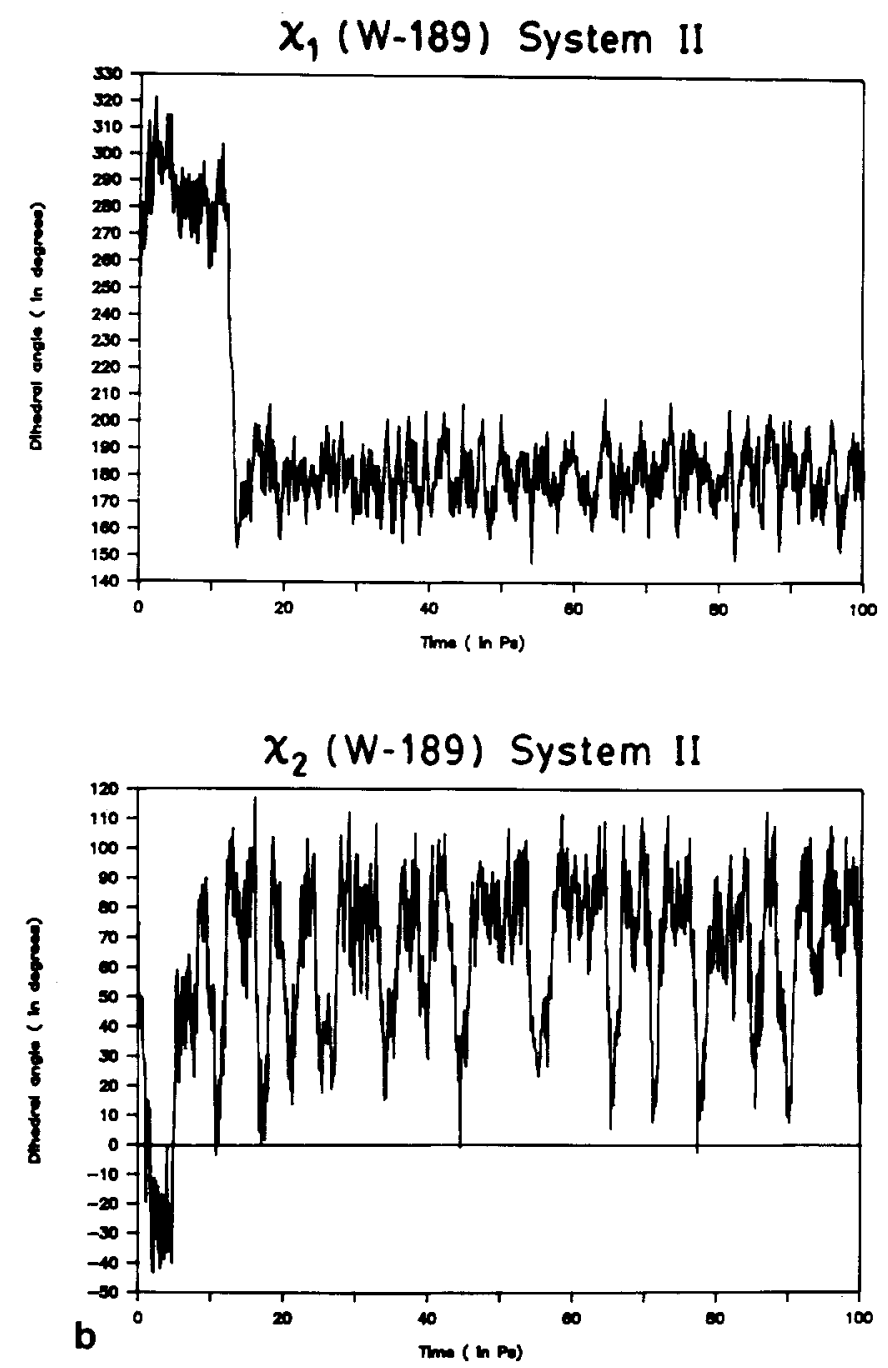

Fig. 8b. Legend appears on page 37.

extreme limits of values that can be taken up by such structures and hence can be useful in interpretation of experimental results.

\section{CONCLUSIONS}

The proline residue in the middle of an $\alpha$-helix has an important role to play in the structure of proteins. The presence of such secondary structures is particularly significant in membrane proteins. The following features have emerged from the present MD studies on helix F model of bacteriorhodopsin (BR) as well as from our recent crystal structure analysis. ${ }^{3}$

1. Some of the backbone internal parameters in the helical turn ending with proline deviate from ideal $\alpha$-helical values.

2. The deviations in the internal parameters from an ideal $\alpha$-helix give rise to a bend in the helix. This bend can be characterized directly by several parameters such as kink angle $(\alpha)$, wobble angle $(\theta)$, vir- tual torsion angle $\mathrm{C}_{\mathrm{p}-3}^{\alpha}-\mathrm{C}_{\mathrm{p}-2}^{\alpha}-\mathrm{C}_{\mathrm{p}-1}^{\alpha}-\mathrm{C}_{\mathrm{p}}^{\alpha}(\rho)$, and a specific hydrogen bond $\left(\mathrm{O}_{\mathrm{p}-3} \ldots \mathrm{N}_{\mathrm{p}+1}\right)$. These parameters are evaluated for the MD simulated structures. The MD average and the rms fluctuations are given for all parameters. The MD trajectories of the bend related parameters show that the helix frequently fluctuates between an ideal $\alpha$-helix and a bent structure. A high degree of correlation is exhibited between the bend related parameters. Among the backbone internal parameters, only the dihedral angle $\phi_{p-1}$ is correlated to a reasonable extent with the bend.

3 . The nature of distortions in the proline region is characterized in detail in terms of related secondary structures such as $\alpha_{\mathrm{I}}, \alpha_{\mathrm{II}}$ and goniometric helices. The interpretation of the experimental results regarding the secondary structures of membrane proteins are discussed.

4. The MD average side chain conformations of helix F model of BR (Trp-182, Tyr-185, Trp-189) is 

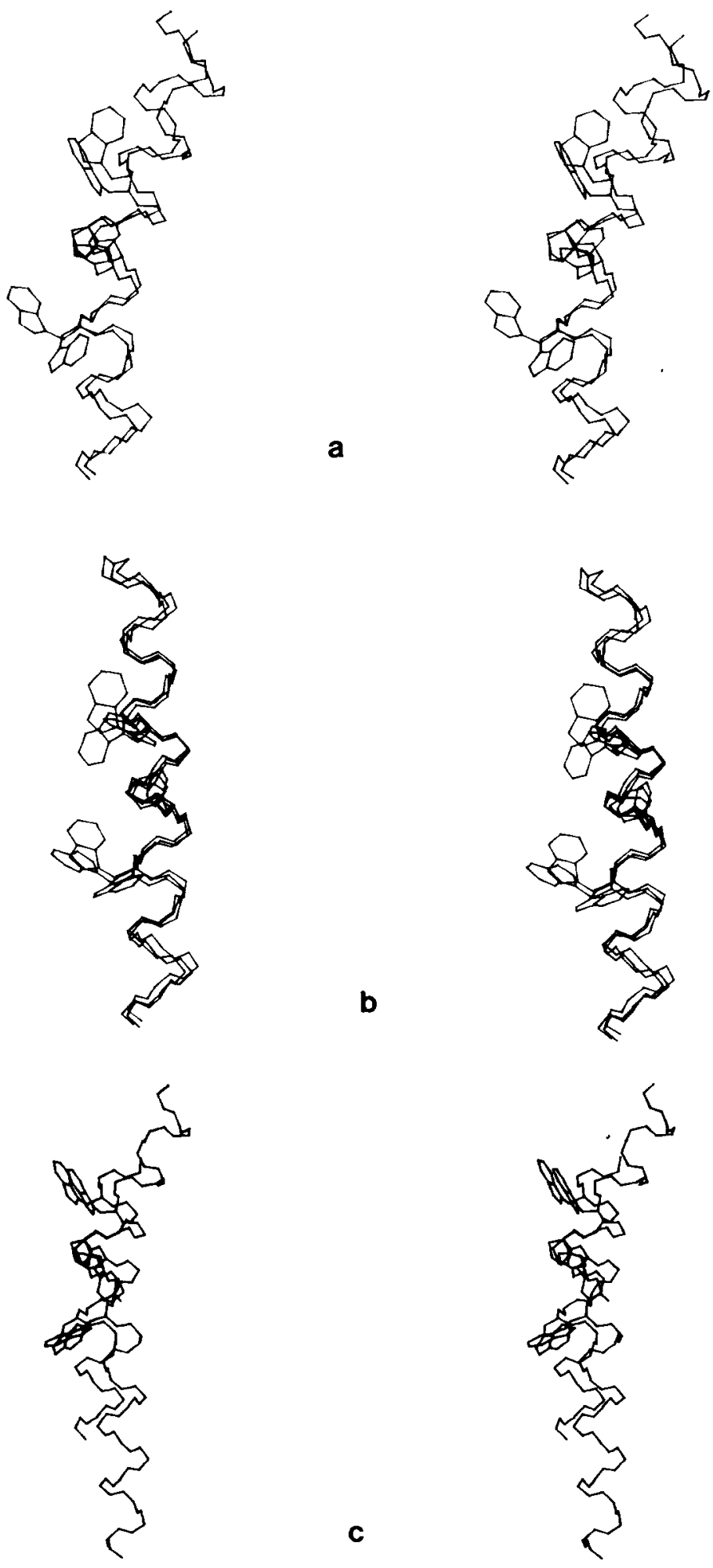

Fig. 9. (a) Stereo diagram of two structures of system I (without alanine residues) are superposed. One of them corresponds to the MD average structure given in Table IV and the other structure is close to the starting conformation obtained at the beginning of the equilibration. (b) Stereo diagram of three structures of system II (without alanine residue) in which the side chain orientations are different. Two of the plotted structures were obtained at $10 \mathrm{ps}\left(\chi_{1}(W-182)=-167.1^{\circ} ; \chi_{2}(W-182)=69.5^{\circ} ; x_{1}(Y-185)=\right.$

168.9 $\left.; \chi_{1}(W-189)=-78.8^{\circ} ; \chi_{2}(W-189)=45.8^{\circ}\right)$ and at 90 ps $\left(\chi_{1}(W-182)=-72.9^{\circ} ; \chi_{2}(W-182)=174.7^{\circ} ; \chi_{1}(Y-185)=167.8^{\circ} ;\right.$ $\left.x_{1}(W-189)=-172.8^{\circ} ; x_{2}(W-189)=13.4^{\circ}\right)$. The third structure is close to the starting conformation. (c) Stereo diagram of the average structure obtained for system I superposed on the crystal structure of the helix F of BR (only trptophan, tryosine, and proline residues are represented and the values corresponding to the conformation of these residues are given in Table VI). 
TABLE V. Average and rms Fluctuations of Tryptophan and Tyrosine Side Chain Dihedral Angles (in Degrees)*

\begin{tabular}{lrrr}
\hline $\begin{array}{l}\text { Side chain } \\
\text { dihedral angle }\end{array}$ & System I & \multicolumn{1}{c}{ System II } & $\begin{array}{c}\text { In bacterio- } \\
\text { rhodopsin }\end{array}$ \\
\hline$\chi_{1}(\mathrm{~W}-182)$ & $-56.0( \pm 10.9)$ & $-156.2( \pm 47.7)$ & -79.2 \\
$\chi_{2}(\mathrm{~W}-182)$ & $154.0( \pm 18.7)$ & $91.9( \pm 31.7)$ & 177.7 \\
$\chi_{1}(\mathrm{Y}-185)$ & $178.0( \pm 10.0)$ & $172.7( \pm 13.8)$ & -65.2 \\
$\chi_{1}(\mathrm{~W}-189)$ & $-179.5( \pm 11.5)$ & $-167.2( \pm 36.3)$ & -145.1 \\
$\chi_{2}(\mathrm{~W}-189)$ & $71.2( \pm 22.8)$ & $62.1( \pm 29.6)$ & 101.5 \\
\hline
\end{tabular}

*The notations for tryptophan and tyrosine residues are W-182, Y-185, and W-189 for systems I and II. This corresponds to the positioning of the residues Trp-182, Tyr-185, and Trp-189 in the helix $F$ of BR. The same nomenclature is followed in the text and also in Figures 6-8.

${ }^{+} \chi_{1}=N \cdot C^{\alpha}-C^{\beta}-C^{\gamma}$

$\chi_{2}=\mathrm{C}^{\alpha}-\mathrm{C}^{\beta}-\mathrm{C}^{\gamma}-\mathrm{C}^{\delta}$

${ }^{7}$ From the coordinates obtained by Henderson (personal communication).

TABLE VI. Standard Helical Parameters for Idealized $\alpha_{\mathbf{I}^{-}}$and $\alpha_{\mathrm{II}^{-}}$-Helical Structures

\begin{tabular}{lcc}
\hline Helical parameters* & $\alpha_{\mathrm{I}}$ & $\alpha_{\text {II }}$ \\
\hline $\mathrm{n}$ & 3.62 & 3.62 \\
$\mathrm{~h}$ & $1.50 \AA$ & $1.50 \AA$ \\
$\phi$ & $-57.4^{\circ}$ & $-70.5^{\circ}$ \\
$\psi$ & $-47.5^{\circ}$ & $-30.0^{\circ}$ \\
$\mathrm{d}(\mathrm{N} \ldots \mathrm{O})$ & $2.86 \AA$ & $3.00 \AA$ \\
$\mathrm{d}(\mathrm{H} \ldots \mathrm{O})$ & $1.88 \AA$ & $2.12 \AA$ \\
$\mathrm{N} \hat{\mathrm{H}} \mathrm{O}$ & $164.2^{\circ}$ & $145.7^{\circ}$ \\
$\mathrm{H} \hat{\mathrm{N}} \mathrm{O}$ & $10.3^{\circ}$ & $23.5^{\circ}$ \\
Distance between H's of & & \\
$\quad$ adjacent NH groups & $2.79 \AA$ & $2.53 \AA$ \\
\hline
\end{tabular}

$*_{n}=$ the number of residues per turn; $h=$ the height per residue; $d(A \ldots B)=$ the distance between atoms $A$ and $B$. See also ref. 32 .

\begin{tabular}{|c|c|}
\hline \multicolumn{2}{|c|}{$\begin{array}{l}\text { TABLE VII. Virtual } \\
\text { Torsion Angle of } \mathbf{C}^{\alpha} \\
\text { Atoms (in Degrees) for } \\
\text { Various Standard } \\
\alpha \text {-Helical Structures }\end{array}$} \\
\hline Description* & Values \\
\hline$x_{I}-\alpha_{I}-\alpha_{I}-\alpha_{I}$ & 50.0 \\
\hline$\alpha_{I^{-}-\alpha_{I I}-\alpha_{I I}-\alpha_{I I}}$ & 50.0 \\
\hline gm-gm-gm-gm & 49.5 \\
\hline$\alpha_{I^{-}} \alpha_{I}-g m-\alpha_{I}$ & 57.6 \\
\hline$\alpha_{I^{I}}-\alpha_{I I}-g m-\alpha_{I}$ & 68.0 \\
\hline
\end{tabular}

*The conformation assumed by each residue is indicated; gm-goniometric helix.

compared with that given for BR structure ${ }^{8}$ and with corresponding position in an ideal $\alpha$-helix. The bend in the helix due to proline gives rise to a specific Trp-182 orientation, which is different if it were to be present in an ideal $\alpha$-helix. Also, the flexibility in the side chain conformations is less in the prolinecontaining helix. The conformation of Tyr-185 in the BR structure is decided by the residues of neighboring helices such as Asp-212.
In summary, the conformation and the flexibility involved in proline-containing $\alpha$-helices are characterized in detail by a set of geometrical parameters. This has aided in quantitative evaluation of the conformational properties of such helices, which acts as a tool for model building and refinement of low-resolution structures. The results on secondary structures of membrane proteins by spectroscopy and the conformational properties of channel forming peptides passing through the membranes can be better understood in light of present studies on prolinecontaining $\alpha$-helices.

\section{ACKNOWLEDGMENTS}

We thank Professor R. Henderson for providing the coordinates of bacteriorhodopsin. R.S. thanks the Council of Scientific and Industrial Research, India, for the Senior Research Fellowship. The work was supported in parts by The CSIR Scheme (No. 9/326/90-EMR-II).

\section{REFERENCES}

1. Richardson, J.S., Richardson, D.C. Principle and patterns of protein conformation. In "Prediction of Protein Structure and Principles of Protein Conformation." Fasman, G.D., ed. New York; Plenum, 1989:48-53.

2. MacArthur, M.W., Thornton, J.M. Influence of proline residues on protein conformation. J. Mol. Biol. 218:397-412, 1991.

3. Sankararamakrishnan, R., Vishveshwara, S. The geometry of proline-containing $\alpha$-helices. Int. J. Peptide Protein Res., in press.

4. Sankararamakrishnan, R., Vishveshwara, S. Conformational studies on peptides with proline in the right-handed $\alpha$-helical region. Biopolymers 30:287-298, 1990.

5. Sankararamakrishnan, R., Sreerama, N., Vishveshwara, $\mathrm{S}$. Characterization of proline-containing right-handed $\alpha$ helix by Molecular dynamics studies. Biophys. Chem. 40: 97-108, 1991.

6. Yun, R.H., Anderson, A., Hermans, J. Proline in $\alpha$-helix: Stability and conformation studied by dynamics simulation. Proteins 10:219-228, 1991.

7. Brandl, C.J., Deber, C.M. Hypothesis about the function of membrane-buried proline residues in transport proteins. Proc. Natl. Acad. Sci. USA 83:917-921, 1986.

8. Henderson, R., Baldwin, J.M., Ceska, T.A., Zemlin, F. Beckmann, E., Downing, K.H. Model for the structure of bacteriorhodopsin based on high-resolution electron cryomicroscopy. J. Mol. Biol. 213:899-929, 1990.

9. Deisenhoferr, J., Epp, O., Miki, K., Huber, R., Michel, H. 
Structure of the protein subunits in the photosynthetic reaction center of $R$ hodopseudomonas viridis at $3 \AA$ resolution. Nature (London) 318:618-624, 1985.

10. Dohlman, H.G., Caron, M.G., Leffowitz, R.J. A family of receptors coupled to guanine nucleotide regulatory proteins. Biochemistry 26:2657-2664, 1987.

11. Consler, T.H., Tsolas, O., Kaback, H.R. Role of proline residues in the structure and function of a membrane transport protein. Biochemistry 30:1291-1298, 1991.

12. Stoeckenius, $W$. The rhodopsin-like pigments of halobacteria: Light-energy and signal transducers in an archaebacterium. Trends Biochem. Sci. 10:483-486, 1985.

13. Williams, K.A., Deber, C.M. Proline residues in transmembrane helices: Structural or dynamic role? Biochemistry 30:8919-8923, 1991 .

14. Soppa, J., Otomo, J., Straub, J., Tittor, J., Meeben, S. Oesterhelt, D. Bacteriorhodopsin mutants of Halobacterium sp. GRB II. Characterization of mutants. J. Biol. Chem. 264:13049-13056, 1989.

15. Lin, S.W., Fodor, S.P.A., Miercke, L.J.W., Shand, R.F., Betlach, M.C., Stroud, R.M., Mathies, R.A. Resonance Raman spectra of bacteriorhodopsin mutants with substitutions at Asp-85, Asp-96, and Arg-82. Photochem. Photobiol. 53:341-346, 1991.

16. Rothschild, K.J., Braiman, M.S., Mogi, T., Stern, L.J., Khorana, H.G. Conserved amino acids in $\mathrm{F}$-helix of bacteriorhodopsin form part of a retinal binding pocket. FEBS Lett. 250:448-452, 1989.

17. Braiman, M.S., Ahl, P.L., Rothschild, K.J. Millisecond Fourier-transform infrared difference spectra of bacteriorhodopsin's $\mathrm{M}_{412}$ photoproduct. Proc. Natl. Acad. Sci. USA 84:5221-5225, 1987 .

18. Gerwert, K., Souvignier, G., Hess, B. Simultaneous monitoring of light-induced changes in protein side-group protonation, chromophore isomerization, and backbone motion of bacteriorhodopsin by time-resolved FourierTransform infrared spectroscopy. Proc. Natl. Acad. Sci. USA 87:9774-9778, 1990.

19. Gibson, N.J., Cassim, J.Y. Nature of forces stabilizing the transmembrane protein bacteriorhodopsin in purple membrane. Biophys. J. 56:769-780, 1989.

20. Koch, M.H.J., Dencher, N.A., Oesterhelt, D., Plohn, H.-J., Rapp, G., Buldt, G. Time-resolved X-ray diffraction study of structural changes associated with the photocycle of bacteriorhodopsin. EMBO J. 10:521-526, 1991.

21. Ormos, P. Infrared spectroscopic demonstration of a conformational change in bacteriorhodopsin involved in proton pumping. Proc. Natl. Acad. Sci. USA 88:473-477, 1991.

22. Weiner, P.K., Kollman, P.A. AMBER: Assisted model building with energy refinement: A general program for modeling molecules and their interactions. J. Comp. Chem. 2:287-303, 1981.

23. Weiner, P.K., Singh, U.C., Kollman, P.A., Caldwell, J., Case, D.A. A molecular mechanics and dynamics program AMBER, University of California, San Franscisco, 1984.

24. Berendsen, H.J.C., Postma, J.P.M., van Gunsteren, W.F., DiNola, A., Haak, J.R. Molecular dynamics with coupling to an external bath. J. Chem. Phys. 81:3684-3690, 1984.

25. Weiner, S.J., Kollman, P.A., Nguyen, D.T., Case, D.A. An all atom force field for simulations of proteins and nucleic acids. J. Comp. Chem. 7:230-252, 1986.

26. Barlow, D.J., Thornton, J.M. Helix geometry in proteins. J. Mol. Biol. 201:601-619, 1988.

27. Chou, K.-C., Nemethy, G., Scheraga, H.A. Energetic approach to the packing of $\alpha$-helices. 2. General treatment of nonequivalent and nonregular helices. J. Am. Chem. Soc. 106:3161-3170, 1984

28. Arnott, S., Wonacott, A.J. Atomic coordinates for an $\alpha-$ helix: Refinement of the crystal structure of $\alpha$-poly-Lalanine. J. Mol. Biol. 21:371-383, 1966.

29. Presta, L.G., Rose, G.D. Helix signals in proteins. Science 240:1632-1641, 1988.

30. Momany, F.A., McGuire, R.F., Burgess, A.W., Scheraga, H.A. Energy parameters in polypeptides VII. Geometric parameters, hydrogen bond interactions and intrinsic torsional potentials for the naturally occurring amino acids. J. Phys. Chem. 79:2361-2381, 1975.

31. Ramakrishnan, C., Soman, K.V. Identification of secondary structures in globular proteins: A new algorithm. Int. J. Peptide Protein Res. 20:218-237, 1982.

32. Dwivedi, A.M., Krimm, S. Vibrational analysis of peptides, polypeptides, and proteins. XVIII. Conformational sensitivity of the $\alpha$-helix spectrum: $\alpha_{\mathrm{r}^{-}}$and $\alpha_{\mathrm{II}}$-Poly (Lalanine). Biopolymers 23:923-943, 1984.

33. Dempsey, C.E., Bazzo, R., Harvey, T.S., Syperek, I., Boheim, G., Campbell, I.D. Contribution of Proline-14 to the structure and actions of melittin. FEBS Lett. 281:240-244, 1991.

34. Bazzo, R., Tappin, M.J., Pastore, A., Harvey, T.S., Carver, J.A. Campbell, I.D. The structure of melittin. A ${ }^{1} \mathrm{H}-\mathrm{NMR}$ study in methonal. Eur. J. Biochem. 173:139-146, 1988.

35. Fox, R.O., Richards, F.M. A voltage gated ion channel model inferred from the crystal structure of alamethicin at $1.5 \AA$ resolution. Nature 300:325-330, 1982.

36. Ramachandran, G.N., Sasisekharan, V. Conformation of polypeptides and proteins. Adv. Protein Chem. 23:283438, 1968 .

37. Nemethy, G., Phillips, D.C., Leach, S.J., Scheraga, H.A. A second right-handed $\alpha$-helical structure with the parameters of Pauling-Corey $\alpha$-helix. Nature (London) 214:363$365,1967$.

38. Colonna-Ceasari, F., Premilat, S., Heitz, F., Spach, G., Lotz, B. Helical structures of Poly (D-L-Peptides). A conformational energy analysis. Macromolecules 10:12841288, 1977.

39. Jackson, M., Haris, P.I., Chapman, D. Fourier-Transform infrared studies of lipids, polypeptides and proteins. J. Mol. Struc. 214:329-355, 1989.

40. Gibson, N.J., Cassim, J.Y. Evidence for an $\alpha_{\text {II }}$ type helical conformation for bacteriorhodopsin in the purple membrane. Biochemistry 28:2134-2139, 1989.

41. Jap, B.K., Maestre, M.F., Hayward, S.B., Glaeser, R.M. Peptide-chain secondary structure of bacteriorhodopsin. Biophys. J. 43:81-89, 1983.

42. Haris, P.I., Chapman, D. Fourier-Transform infrared spectra of the polypeptide alamethicin and a possible structural similarity with bacteriorhodopsin. Biochim. Biophys. Acta 943:375-380, 1988 .

43. Krimm, S., Dwivedi, A.M. Infrared spectrum of purple membrane: Clue to a proton conduction mechanism? Science 216:407-408, 1982 . 